\title{
EVALUATION INDICATORS OF GREEN ECONOMIC DEVELOPMENT: THE CASE OF THE BALTIC COUNTRIES
}

\author{
Rokas Alekna, ${ }^{1}$ Eglè Kazlauskienè ${ }^{2}$ \\ ${ }^{1,2}$ Department of Economics Engineering, Faculty of Business Management, Vilnius Gediminas Technical \\ University, Sauletekio al. 11, LT-10223 Vilnius, Lithuania, \\ lalekna.rokas@gmail.com, ${ }^{2}$ egle.kazlauskiene@vgtu.lt
}

\begin{abstract}
Research purpose. The green economy may become a solution to the existing problems. The European Union must implement solutions related to the green economy in order to solve the existing ecological, economic and social problems in the region, such as pollution in the Baltic Sea region, inequality, greenhouse gas emissions, climate change and so on. It can be assumed that green economy evaluation research conducted in the scientific community does not always reflect the real situation, due to the lack of indicators or limited evaluation methodology. The aim of this article is characterized by academic literature to identify green economic development indicators and evaluate green economic development indices in three Baltic countries: Lithuania, Latvia and Estonia.
\end{abstract}

Design/Methodology/Approach. The article uses analysis of scientific literature, systematization, comparative analysis, generalization and data normalization methods.

Findings. The analysed scientific literature and reports of international organizations, resolutions and conference agreements allow to compile a list of indicators for the evaluation of green economy development. The results showed that in all the analysed countries, a strong growth of green economy development indices can be seen; in Estonia, they remained the best among the three Baltic countries during the analysed period. An analysis of which individual indicators are most important in the development of the green economy and have the greatest significance for the index has shown that their estimates and position have changed significantly in less than two decades.

Originality/Value/Practical implications. The identification of green economy indicators provides a new approach to the structure of green economy components. Indicators measured over time describe the structural characteristics and quantitative changes of the green economy, and provides a new understanding of the opportunities and directions of green economy development. In the framework of this study, fifteen indicators were selected for the analysis of green economy in the Baltic States. The normalization and further evaluation of these indicators from the point of view of the green economy allowed to determine the significance of individual social, economic and environmental dimensions for the overall green economy index and to show the changes over a period. The collected data also form the basis for further in-depth prognostic studies.

Keywords: Green Economy; Indicators of Green Economy; Green Economy Development.

JEL codes: Q01; Q56; O13; O57

\section{Introduction}

The green economy is an area of economic science where policy efforts, technological solutions, societal attitudes and economic actions are focused on ideas that are associated with sustainable development.

The 2012 United Nations Conference on Sustainable Development Rio + 20 adopted an important resolution (A / RES / 66/288 - The Future We Want) emphasizing the importance of the green economy. The Rio + 20 conference emphasized that the green economy is seen as one of the key tools for achieving sustainable development and poverty eradication (United Nations [UNDSD], 2012). In some Western 
European countries, the green economy may become a solution to the existing problems. The European Union must implement solutions related to the green economy in order to solve the existing ecological, economic and social problems in the region, such as pollution in the Baltic Sea region, inequality, greenhouse gas emissions, climate change and so on. It can be assumed that green economy evaluation research conducted in the scientific community does not always reflect the real situation, due to the lack of indicators or limited evaluation methodology. It is therefore possible to discuss the issue, which has not been addressed by - how to identify the indicators that describe the development of a green economy. In the past, multiple scientific community researchers have analysed green economy development with inclusion of multiple different indicator, of which majority includes the problem - lack of consistent data (Law, De Lacy, Lipman, \& Jiang [2016], Kunapatarawong and Martinez-Ros [2016], Sonnenschein and Mundaca [2015], Stankevičienè and Nikanorova [2017], Moyo [2014], Weber and Cabras [2017]). Other scientific scholars mostly use secondary data to assess green economy in certain regions (Islam, Siwar, Ludin, Chowdhury, Ibrahim, 2012). D’Amato, Droste, Allen, Kettunen, Lahtinen, Korhonen, Leskinen, Matthies, and Toppinen (2017) analysed three differences, but similar concepts - circular economy, green economy and bio economy based on machine-learning analysis of literature, and states, that green economy is most inclusive, but all concepts are limited regarding economic growth paradigm. Analysing the given scientific literature, we can see multiple different variations of green economy analysis. We can state, that there exists misconception on how to evaluate green economy development on a global level. Currently, an actual scientific problem: How and on what indicators can the development of the green economy be assessed?

The aim of this article is characterized by academic literature to identify green economic development indicators and evaluate green economic development indices in three Baltic countries: Lithuania, Latvia and Estonia.

Methods: Analysis of scientific literature, systematization, comparative analysis, generalization, data normalization.

Limitations of the research: All macroeconomic and environmental data are collected from publicly available databases: Eurostat, OECD, World Bank. Some data are provided non-periodically. There is a limitation when a large part of the relevant data for the calculation of indices is submitted before 2015, 2016, 2017 or 2018. For indicator data series where data gaps are identified, the arithmetic mean of the existing indicator data series will be added.

Literature Review. The importance of green economy development and identification of evaluation indicators

According to Porfir'ev (2012), green economy can be understood as 'the development, production, and exploitation of technologies and equipment for controlling and reducing pollutants and greenhouse gas emissions and for monitoring and forecasting climate changes, as well as energy saving, resource saving, and renewable energy technologies' (p. 120). According to International Chamber of Commerce (hereinafter ICC) (2012), the description of green economy is stated as 'in which economic growth and environmental responsibility work together in a mutually reinforcing fashion while supporting progress on social development' (ICC, 2012). The green economy depends on economic (environmental costs, investment in renewable energy, labour, poverty, etc.), social (social rights, guarantees, public consumption habits, etc.), technological (development and use of new technologies), ecological (biodiversity conservation, climate change, air quality and pollution, waste management, use of renewable energy sources, use of fossil fuels), political (legislation and the state's approach to the green economy) factors. Every factor is important for the development of the green economy. Researchers link the descriptions of the green economy to the creation of economic prosperity and environmental protection, with a strong focus on reducing carbon emissions.

It should be emphasized that the green economy can be considered as a tool for sustainable development endeavours and green economic development requires political restructuring and investment 'Working towards a Balanced and Illusive Green Economy' (UNEP, 2011). Achieving sustainable development is a key goal of the green economy (Maran and Nedelea, 2017). Nieto, Carpintero and Miguel (2018) conducted a study to see if the Paris Agreement can have a real impact on climate change and the economy. Scientists (Nieto et al., 2018) concluded that even under the terms of the Paris Agreement, 
global temperatures should rise by 3 degrees Celsius compared to the pre-industrial period, although changes will depend on the consumption and production patterns of the developed countries. Gultekin, Erenoglu (2018) studied the green economy and emphasized the importance of public policy, highlighting in the conclusions that: 'some countries see development and industrialization policies in front of clean environmental policies. This situation causes the policies towards green economy to be delayed or prevented' (p. 855). An analysis of the scientific literature shows positive examples of the introduction of the green economy - more jobs can be one of the main benefits, regardless of the reduced impact on nature. According to Abu Jamie (2018), 'the adoption of green economy has a positive impact on the States' performance, which will improve the green economy indicators as well. This will lead to an improvement in the economic growth rate. We can say that the green economy offers practical solutions to the problems of poverty, unemployment, and the depletion of resources while maintaining growth levels' (p. 128). It can be concluded that the green economy may become a solution for countries striving for higher economic growth, but according to Abu Jamie (2018), 'relation between adoption of green economy and economy growth may not be established in the first steps of adoption due to the high investment cost in the implementation of green economy strategies' (p. 128).

A similar remark made by Loiseau et. al. (2016) emphasizes that strategies for green economy implementation can be incremental. According to Loiseau et. al. (2016), 'certain solutions are more compliant with mainstream economy and require few changes, whereas other solutions are based on deep transformations of our patterns of production and consumption like industrial ecology or naturebased solutions that require large-scale investments into green infrastructure' (p. 17). In other words, researchers emphasize that the green economy can be an exceptionally important tool in terms of environmental and economic benefits. However, researchers point out that this mutual benefit is not always easily achieved. Barber and Markandya (2013) stated scepticism about the effectiveness of measures in delivering of jobs and improving environment due to lack of political will, concerns about increasing government budgets, deficits when talking about green economy.

It can be assumed that while the green economy can bring significant benefits, it is important to keep in mind the potential negative effects and their magnitude. New facilities (such as wind farms) require space, which can disrupt biodiversity and the landscape, and investors who invest in developing countries may have interests other than return on investment. This poses significant challenges for the development of the green economy, which raises the fundamental question of whether the idea of a green economy is effective. In 2018, examples of the use of the green economy were systematized and analysed according to the decisions made by different countries. Examples of applications of the green economy provided by scientists cover a wide range of economic, technological, social and environmental areas: reduction of fossil fuels, use of renewable energy sources, poverty, greenhouse gas emissions, investment in development of new, green and cost-effective technologies (Gultekin, Erenoglu, 2018). Researchers also stressed the importance of public policy.

In 2012, a survey on the development trends of the green economy was conducted (Porfir'ev, 2012). The researcher stated that the green sector is still small in a global context: 'the estimated value of goods and services produced is $\$ 2$ trillion or $2.7 \%$ of the GWP, the estimated profit is $\$ 530$ billion, and employment is about 10 million people' (Porfir'ev, 2012 p. 120). For the analysis of green economy, the researcher used indicators such as: share of green sector in the gross domestic product (hereinafter GDP), investment in the green sector and technology, labour force in the green sector and profits made by business. The researcher emphasized that the problem itself is the low growth of the sector, low investment in green technologies and job creation. It can be emphasized that the green economy must be related not only to ecological or social areas and indicators focused on it, but also to financial and economic indicators. State decisions and policies play a key role in the development of the green economy, as taxes, incentives and permits can depend on it.

Global regulations or internationally agreed cross-border agreements may be taken into account for the assessment of the green economy in a global context. One of the most important agreements are 'Kyoto Protocol to the United Nations Framework Convention on Climate Change' (hereinafter 'Kyoto Protocol') (UN, 1998). The main goal of the Kyoto Protocol was to reduce emissions of 6 key greenhouse gases (carbon dioxide $\mathrm{CO}_{2}$, methane $\mathrm{CH}_{4}$, nitrous oxide $\mathrm{N}_{2} \mathrm{O}$, hydrofluorocarbons $\mathrm{HFCs}$, perfluorocarbons PFC, sulphur hexafluoride $\mathrm{SF}_{6}$ ) (United Nations Climate Change, 2019). 
In addition to the Kyoto Protocol, there is another important ruling on climate change - 'Paris agreement' (UN, 2015). The main purpose of this agreement is to ensure that the temperature of planet Earth does not rise by $1.5^{\circ} \mathrm{C}$ by the end of this century compared to the pre-industrial period. This agreement not only regulates pollution that has a direct impact on climate change, but also increases investment in measures to prevent and respond to natural disasters (UN, 2015).

In order to analyse the development of the green economy, it is necessary to clarify and identify the indicators needed for the analysis. Sonnenschein and Mundaca (2015) assessed the green economy in South Korea. For the study, the researchers selected carbon dioxide $\left(\mathrm{CO}_{2}\right)$ emissions (estimated emissions from fuel combustion, excluding emissions from shipping and aviation), total primary energy supply (as an indicator of energy production, imports and changes in available stocks excluding exports), total final energy consumption (total consumption from different consumer sectors), gross domestic product and the entire population of South Korea, regardless of nationality or age.

Pan et al. (2018) evaluated the green economy in China, and selected empirical data for the study according to various economic, energy, ecological indicators: labour, capital, energy, GDP and $\mathrm{CO}_{2}$. Researchers Pan et al., (2018) additionally grouped all indicators into new groups: urbanization, energy consumption structure and industry structure.

Abu Jamie (2018) conducted an empirical study to assess how the adaptation of the green economy affects the concept of sustainable development and the achievement of goals. For the evaluation, the researcher used economic indicators (net GDP, GDP growth rate, GDP per capita), indicators describing the environment, natural capital and climate change, efficiency indicators, investments in environmental protection. It is important to note that the researcher (Abu Jamie, 2018) systematized environmental and natural capital, climate change indicators, efficiency indicators, and investment in the environment into a separate index of green economy that was compared to GDP indicators.

Unay-Gailhard and Bojnec (2019) investigated the application of green economy principles in Slovenian farms. For the study, the researchers used agricultural land as a factor, classified them according to yield indicators, and singled out the areas in which farmers used the principles related to the green economy in their activities. The researchers compared the data of agricultural land with the changes in the lab or force on the same farms. Such an example of green economy research can be used, but in order to accurately assess the development trends of the green economy, it is necessary to evaluate the green economy from a broader perspective.

Stankevičienė and Nikanorova (2017) analysed economic and ecological well-being in the context of the circular economy. The researchers chose indicators that also reflect the ideas of the green economy: municipal waste recycling rate (\%), e-waste recycling rate (\%), amount of landfills excluding basic mineral waste (\%), eco-innovation index, share of renewable energy\% from final energy consumption, greenhouse gas emissions from energy consumption, share of renewable energy in transport fuel consumption, environmental tax revenue, energy taxes per GDP, energy consumption per GDP, energy production per GDP, renewable energy consumption per GDP, renewable energy production per GDP, value added of non-financial business economy, energy efficiency, resource efficiency, electricity produced from renewable sources, renewable energy consumption, energy production, renewable energy production. Such an extensive list of indicators can provide an opportunity to analyse in detail the development of the green economy. Taking into account the indicators analysed by Stankevičiene and Nikanorova (2017), it can be noticed that they can be supplemented with social, technological and political factors.

The indicators analysed by Nahman, Mahumani and de Lange (2016) may explain the development of the green economy, but the researchers note that not all indicators are developed, or the data are insufficient for inclusion in the study. The analysed scientific literature and reports of international organizations, resolutions, conference agreements allow to compile a list of indicators for the evaluation of green economy development. This can be done by developing a matrix where one axis of the matrix presents all the indicators analysed and the other axis shows the researchers, the international organizations that included the indicator in the analysis.

The resulting matrix is presented in Table 1. Most often mentioned are the indicators of GDP (gross 
domestic product), greenhouse gas emissions, labour, total primary energy consumption and energy efficiency. Indicators that are most mentioned in other works, have been mentioned more than 4 times. The least mentioned indicators are poverty line (or poverty gap), ecosystems, biodiversity, indoor air pollution, good governance and so on. It can be mentioned that none of the other analysed literature used foreign direct investment, wage and inflation indicators.

Table 1. Indicators of Green economic development (Source: author's compilation, based on EC (2018) ${ }^{1}$; Porfir'ev $(2012)^{2}$; Sonnenschein \& Mundaca (2015) $)^{3}$; Pan et. al. (2018) ${ }^{4}$; Abu Jamie (2018) ; Unay-Gailhard \& Bojnec (2019) ${ }^{6}$; Stankevičienė \& Nikanorova $(2017)^{7}$; Nahman et al., 2016 ${ }^{8}$ )

\begin{tabular}{|c|c|c|c|c|c|c|c|c|c|}
\hline Indicators & 1 & 2 & 3 & 4 & 5 & 6 & 7 & 8 & Total \\
\hline Greenhouse gas emissions & & & + & + & & & + & + & 4 \\
\hline GDP & & + & + & + & + & & + & & 5 \\
\hline Labour & & + & & + & & + & & + & 4 \\
\hline Total primary energy supply (TPES) & & & + & & & & + & + & 3 \\
\hline Total primary energy consumption & & & + & + & & & + & + & 4 \\
\hline $\begin{array}{l}\text { The share of energy consumed from renewable } \\
\text { energy sources }\end{array}$ & & & & + & & & + & + & 3 \\
\hline $\begin{array}{l}\text { The share of energy consumed from renewable } \\
\text { energy sources }\end{array}$ & & & & + & & & + & + & 3 \\
\hline GDP growth rate & & & & & + & & & & 1 \\
\hline GDP per capita & & & & & + & & & & 1 \\
\hline Energy efficiency & + & & & & + & & + & + & 4 \\
\hline Investment in the environment & & + & & & + & & & + & 3 \\
\hline Area of agricultural land & & & & & & + & & + & 2 \\
\hline $\begin{array}{l}\text { Recycling of municipal waste, from all municipal } \\
\text { waste }\end{array}$ & + & & & & & & + & & 2 \\
\hline E-waste recycling rate & & & & & & & + & & 1 \\
\hline Number of landfills excluding basic mineral wastes & & & & & & & + & & 1 \\
\hline Environmental taxes collected & & & & & & & + & & 1 \\
\hline Good governance & & & & & & & & + & 1 \\
\hline New patents related to the environment & & & & & & & & + & 1 \\
\hline Gèlo vandens gavyba tenkanti vienam gyventojui & & & & & & & & + & 1 \\
\hline Waste disposed per capita & & & & & & & & + & 1 \\
\hline Indoor air pollution, $\mathrm{PM} 2.5$ and $\mathrm{SO}_{2}$ emissions & & & & & & & & + & 1 \\
\hline $\begin{array}{l}\text { Natural capital (percentage of marine and terrestrial } \\
\text { protected area of the total area) }\end{array}$ & + & & & & + & & & + & 3 \\
\hline $\begin{array}{l}\text { Biodiversity (ratio of endangered plant and animal } \\
\text { species to all known species) }\end{array}$ & & & & & & & & + & 1 \\
\hline $\begin{array}{l}\text { Ecosystems (total area of agriculture, planted forests } \\
\text { and cities as a percentage of the total area) }\end{array}$ & & & & & & & & + & 1 \\
\hline $\begin{array}{l}\text { Average poverty line deficit (based on purchasing } \\
\text { power parity), expressed as a percentage of the } \\
\text { poverty line }\end{array}$ & & & & & & & & + & 1 \\
\hline
\end{tabular}


It can be argued that in order to assess the green economy, research should be based on indicators that describe the greenhouse gas emissions, GDP, labour force, primary energy consumption and production, and energy produced and consumed from renewable sources (share of total energy), energy efficiency (or productivity), investment in environmental protection, agricultural land, municipal waste recycling, natural capital. Indicators measured over time describe the structural characteristics and quantitative changes of the green economy, and provides a new understanding of the opportunities and directions of green economy development. The identification of green economy indicators provides a new approach to the structure of green economy components. Based on the analysis of indicators of various scientific fields (economy, environmental), the complexity of the evaluation of the green economy is emphasized.

\section{Methodology}

The study analyses the countries: Lithuania, Latvia and Estonia. All macroeconomic and environmental data are collected from publicly available databases: Eurostat, OECD and World Bank. The dynamics of green economy development indicators will not answer the questions raised. Thus, in the first stage, it is necessary to identify which methods of empirical data management and calculation can be applied in the study.

Nahman, Mahumani and de Lange (2016) proposed a green economy index (GEI), which consists of normalized indicators describing the green economy. After collecting the data, the researchers (Nahman et al., 2016) performed data normalization for the selected indicator. To perform data normalization, the researchers chose 2 formulas:

where higher raw values are desirable (as the indicator increases, economic, ecological and social wellbeing improves):

$$
x_{i}^{\prime}=\frac{x_{i}-\min (x)}{\max (x)-\min (x)},
$$

where lower raw values are desirable (as the indicator declines, economic, ecological and social well-being improves):

$$
x_{i}^{\prime}=\frac{\max (x)-x_{i}}{\max (x)-\min (x)},
$$

Here:

$x_{i}-$ the value of the indicator during the period $i$;

$\max (x)$ - the maximum value of the indicator during the analysed period;

$\max (y)$ - the minimum value of the indicator during the analysed period.

The resulting normalized indicators were calculated by researchers (Nahman et al., 2016) to calculate the arithmetic mean of all normalized indicators for each country, which reflected the green economy index. Such a green economy index is advantageous because it measures a large part of the indicators describing the green economy. However, there is a major shortcoming of this study related to data retrieval - not all indicators are developed, or the data are insufficient for inclusion in the study. It should be noted that there is no common understanding among researchers about how the green economy should be viewed. For example, the green economy index proposed by Fankhauser, Kazaglis and Srivastav (2017) reflects the trend of technological development but does not reveal the characteristics of other indicators of the green economy. The Green Economy Index, presented by Holger et al. (2017), evaluates the green economy from a broader perspective, but it becomes unclear due to the choice of certain indicators. Nahman et al. (2016) provide a green economy index along with detailed indicators but not all indicators are developed, or the data are insufficient for inclusion in the study.

However, this study will be based in part on Nahman et al. (2016) methodology for compiling green economy indices. In the second stage, it is important to select the data needed for the study. It is also important to assess the evolution of the indicators at the sampling stage of the following data: Poverty 
gap (\% of the population at $\$ 1.9$ per day); Greenhouse gas emissions, thousand $\mathrm{T}$. $\mathrm{CO}_{2}$ equivalent; Labour force; Total primary energy supply, (tonnes of oil equivalent, hereinafter TOE); Total primary energy consumption, (TOE); Renewable energy supply, \% TPES; Share of electricity from renewable sources, Percentage; Total government expenditure on environmental protection, mln. Eur; Areas of agricultural land (\% of total land area); Municipal waste recycling \% from all municipal waste; Land protected area, $\mathrm{Km}^{2}$; Marine protected area, $\mathrm{Km}^{2}$; Good Governance index; Newly created patents that are directly related to the environment; Foreign direct investment, mln. USD.

In the third stage, the green economy index is calculated. The green economy index is based on normalized indicator data and by averaging normalized data. In this way, the data is made comparable. When analysing the characteristics of the data, attention should first be paid to the unequal periodicity of the available macroeconomic data. Data are provided periodically, for a period of one year, but some data are provided more than 2 years ago. It is also possible to detect the year when data are not provided. This may adversely affect the test results. Similar studies in the past have also been based on annual national data, so the available data are acceptable.

Due to lack of data, the study considered the beginning of the year 2000. There is a limitation when a large part of the relevant data for the calculation of indices is submitted before 2015, 2016, 2017 or 2018. A large part of the data is not provided to the European Statistical Office (hereinafter Eurostat), the World Bank, the International Organization for Economic Co-operation and Development (hereinafter OECD). Some data are not provided for 2018, 2017 or 2016. This will be considered in further research. Due to the lack of data, country data provided by Eurostat, OECD, World Bank will be analysed. In order to assess the development of the green economy, the index of normalized green economy indicators (arithmetic mean of X'i normalized indicators) will be used (Nahman et al., 2016). The data are calculated for each country based on the available macroeconomic and environmental data. For illustration (Table 2.), data of the analysed countries for a fragmented period are presented. According to OECD (2019), the number of patents is presented in fraction, because there is a need to eliminate multiple counting of patents, if it was invented by several different inventors from different countries. For example, if a patent is co-invented by 1 Lithuanian, 1 Latvian and 2 Estonian residents, it will be counted as:

- $\quad 1 / 4$ of a patent for Lithuania;

- $1 / 4$ for the Latvia;

- and 1/2 patent for Estonia.

Table 2. Macroeconomic and environmental data (Source: author's compilation, by Eurostat (2019), OECD (2019), World Bank (2019))

\begin{tabular}{|l|l|l|l|l|l|l|}
\hline \multirow{2}{*}{ Indicators } & \multicolumn{2}{l|}{ Lithuania } & \multicolumn{2}{l|}{ Latvia } & \multicolumn{2}{l|}{ Estonia } \\
\cline { 2 - 7 } & 2015 & 2017 & 2015 & 2017 & 2015 & 2017 \\
\hline Poverty gap at \$1.90 a day (2011 PPP) (\%) & 0.5 & & 0.7 & & 0.5 & \\
\hline Foreign direct investment, mln, USD & 870.5047 & 652.5081 & 707.709 & 732.724 & 35.6483 & 1712.78 \\
\hline $\begin{array}{l}\text { Greenhouse gas emissions, thous. T. CO } \\
\text { equivalent }\end{array}$ & 20452.77 & 20737.67 & 11603.4 & 11755.8 & 18278.2 & 21060.7 \\
\hline $\begin{array}{l}\text { Newly created patents that are directly } \\
\text { related to the environment }\end{array}$ & 4.7714 & & 2 & & 2.2 & \\
\hline $\begin{array}{l}\text { Municipal waste recycling \% from all } \\
\text { municipal waste }\end{array}$ & 23.256 & 24.371 & 24.649 & 19.167 & 27.033 & 25.72 \\
\hline $\begin{array}{l}\text { Total government expenditure on } \\
\text { environmental protection, mln. EUR }\end{array}$ & 201.3 & 175 & 161.8 & 151.5 & 150 & 176.8 \\
\hline \begin{tabular}{l} 
Good Governance index \\
\hline
\end{tabular} & 0.970229 & 0.904817 & 0.788549 & 0.797347 & 1.19506 & 1.189771 \\
\hline
\end{tabular}




\begin{tabular}{|l|c|c|c|c|c|c|} 
Renewable energy supply, \% TPES & 20.09359 & 12.90016 & 36.05442 & 40.38868 & 16.55702 & 16.8884 \\
\hline Renewable energy \%, from total energy & 25.751 & 25.835 & 37.539 & 39.01 & 28.35 & 29.21 \\
\hline Labour force & 1470309 & 1469107 & 1011483 & 1004754 & 686173 & 702172 \\
\hline Land protected area, Km ${ }^{2}$ & 10976.65 & 11000.23 & 11723.94 & 11724.03 & 8761.703 & 8795.723 \\
\hline Marine protected area, Km ${ }^{2}$ & 1562.13 & 1562.13 & 4628.7 & 4628.7 & 7024.235 & 7024.235 \\
\hline Total primary energy supply (TOE) & 7.052 & 8.130352 & 4.263 & 4.734 & 5.472 & 5.412 \\
\hline $\begin{array}{l}\text { Total primary energy consumption, (TOE) } \\
\text { Areas of agricultural land } \\
\text { (\% of total land area) }\end{array}$ & 5,79 & 6,16 & 4,27 & 4,47 & 5,32 & 5,64 \\
\hline $\begin{array}{l}\text { Share of electricity from renewable } \\
\text { sources, Percentage }\end{array}$ & 39.40817 & 16.20439 & 50.1717 & 72.51361 & 14.44509 & 13.24715 \\
\hline \begin{tabular}{l} 
GDP per capita, USD \\
\hline
\end{tabular} & 14291.90 & 16809.64 & 13639.69 & 15684.56 & 17412.45 & 20200.38 \\
\hline
\end{tabular}

It should be noted that not all countries present the indicators for the same period, so the results obtained may not be completely accurate. Nahman et al. (2016) also encountered the same limitation in their study. The researchers addressed this issue by replacing the missing data with arithmetic means. Such a methodology will be chosen in this work as well. For indicator data series where data gaps are identified, the arithmetic mean of the existing indicator data series will be added. Such a methodology is applied in other works and is widely described in scientific works and is considered as one of the simplest methodologies (Kang, 2013).

\section{Results. Changes in green economy indices}

The green economy index was calculated on the basis of available macroeconomic environmental indicators. The calculated results are presented in Figure 1. The results obtained in the study by Nahman et al. (2016) were multiplied by 10 (the aim was to reveal the assessment in a ten-point system). In this case, the results are displayed as they were during the calculation. The closer the indicator is to 1 , the stronger the development of the green economy is considered. Analysing the obtained results, it can be stated that in all the analysed countries, a strong growth of green economy development indices can be seen.

Paying attention to the latest data (2018), it can be noted that Lithuania has the lowest result, but the situation is very similar in Latvia. It can be said that the progress of the green economy in these regions is the lowest, but it is worth noting that some data were not provided in 2018, which may have significantly affected the results of the index. 


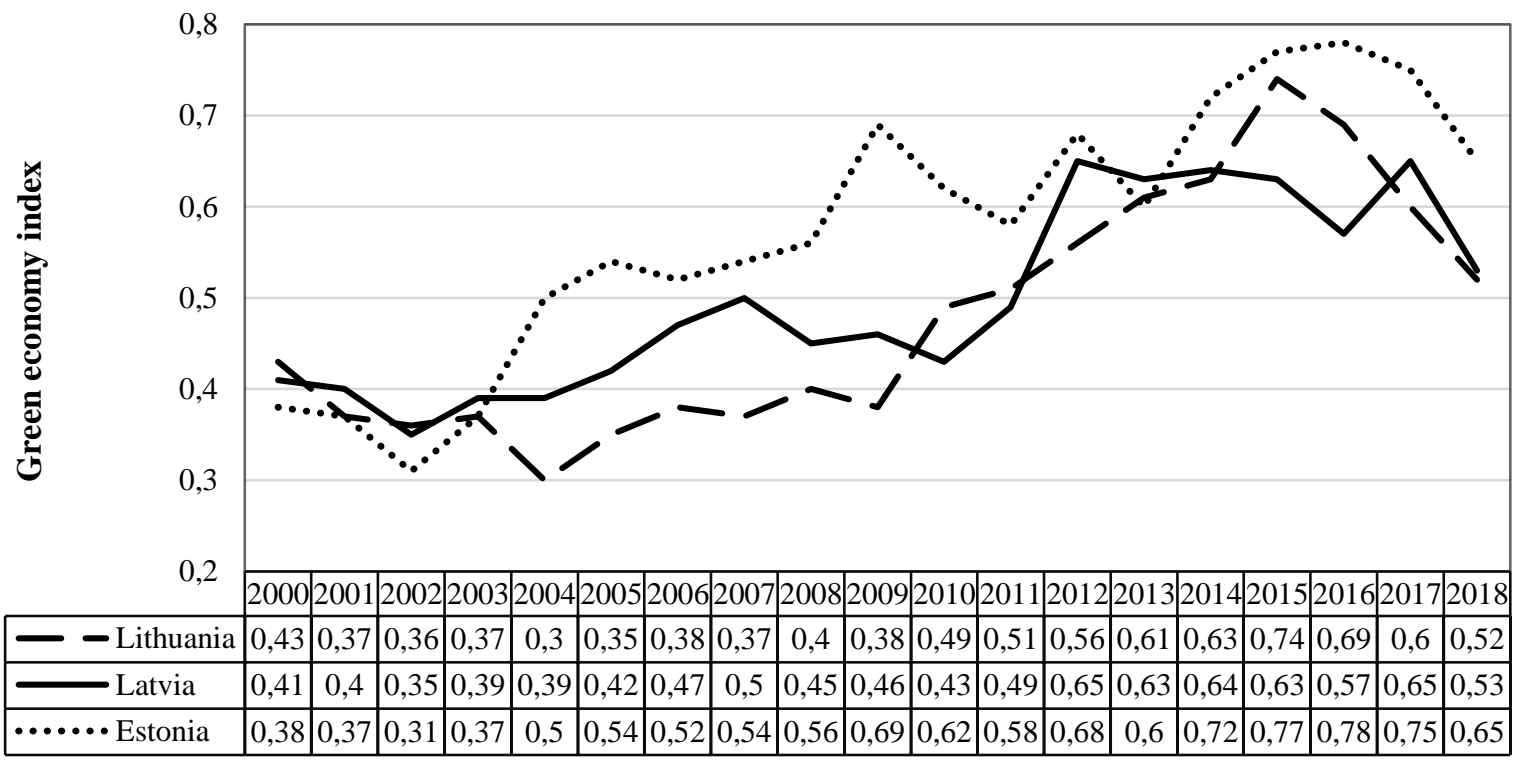

Fig. 1. Green economy index 2000-2018 (Source: author's compilation)

It can be stated that the green economy is the most developed in Estonia (according to the data obtained in 2018, presented in Fig.1). However, when analysing the data, a significant question arises - which indicators are the most important for the development of the green economy. This can be answered by analysing the compiled index in detail. Since the index is calculated based on the arithmetic average of the normalized values of the indicators describing the green economy, it is possible to analyse the normalized values of each of the indicators separately, distinguishing the most important ones. In order to assess the development, the period from 2000 to 2018 will be analysed.

Data on Lithuania's results are presented in Figure 2. It should be emphasized that primary energy consumption, greenhouse gas emissions, poverty line indicators are the inverse - the closer the data is to 0 - the more significant the development of the green economy.

Analysing the data, it can be emphasized that in 2000, in the field of green economy in Lithuania, significance existed for electricity, which is extracted from renewable sources and labour. The labour force in 2000 was the largest in the study period, and since then the labour force in Lithuania has only been declining. It can also be emphasized that in 2000, the indicators of municipal waste recycling were more significant than in 2018. This shows that there are untapped opportunities in this area in Lithuania that can be developed. 


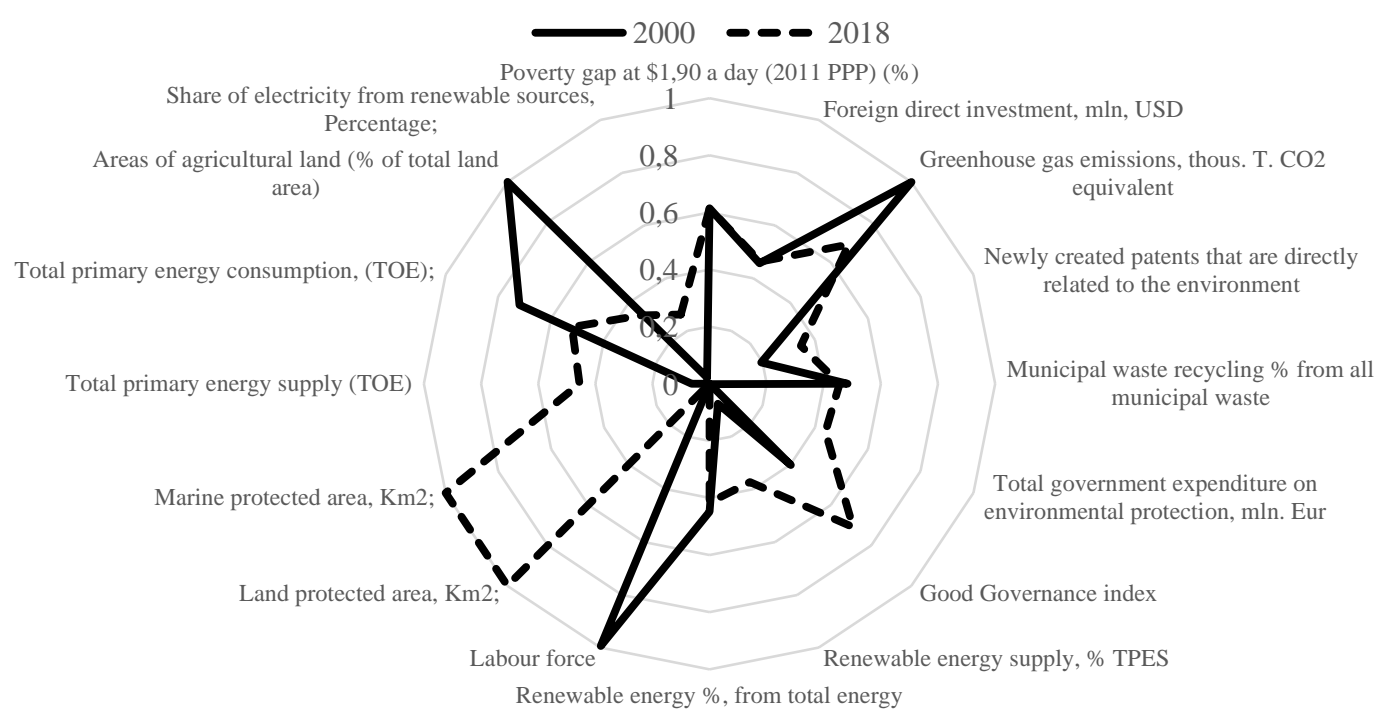

Fig. 2. Normalized indicators for the green economy. Lithuanian data (Source: Eurostat (2019), OECD (2019), World Bank (2019) data)

Considering the data of 2018, it is possible to emphasize the significant development in the following indicators: protected areas, good governance, renewable energy supply, government expenditure, newly created patents. In 2018, the importance of primary energy consumption for the green economy is recorded. This shows that the available energy resources are used more efficiently compared to 2000 . Greenhouse gas indicators show significant changes during the analysed period, which reveals that the measures taken by the state are effective, but still, these did not provide the desired result. It can also be emphasized that no significant change in the poverty line indicators has been recorded. This reveals that comparing the period of 2000 and 2018, the poverty level in Lithuania did not change much.

Data for Latvia are presented in Figure 3. Comparing the results of 2000 and 2018, it can be stated that the changes are in the following areas: agricultural land, primary energy consumption, primary energy supply, marine and terrestrial protected areas, renewable energy supply, good governance, government expenditure, and greenhouse gas emissions.

Changes in primary energy consumption can be highlighted in the analysis. It can be said that the changed technological environment has provided new opportunities for efficient use of available energy resources, and the increased supply of renewable energy allows for less pollution. The data obtained also show indicators where there is no significant change, which are: foreign direct investment, poverty line, new patents and municipal waste recycling. It can be concluded that the field of energy is very important in Latvia, but more attention needs to be paid to waste recycling, poverty reduction and the development of new technologies. It can also be emphasized that labour force indicators show a similar situation as in Lithuania. 


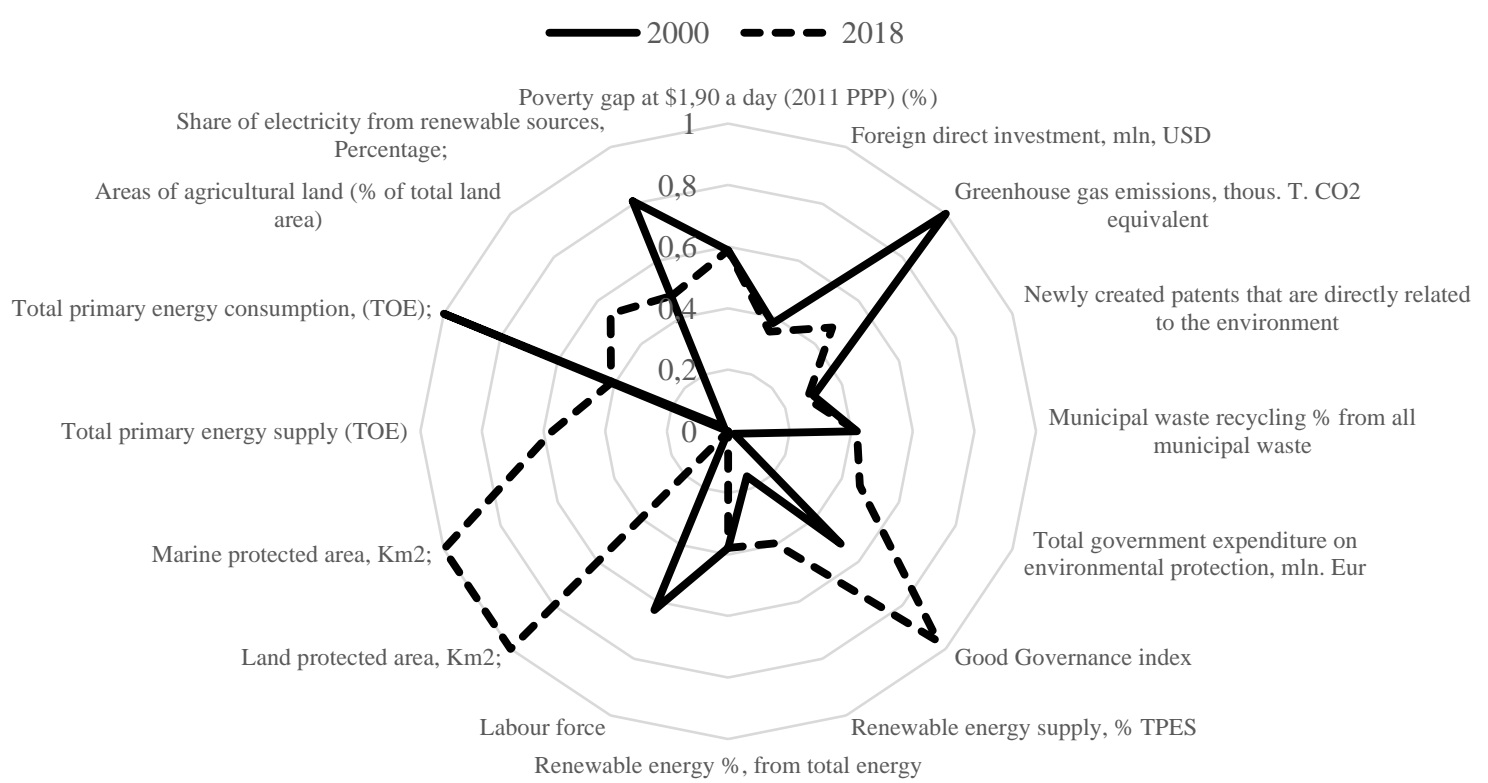

Fig. 3. Normalized indicators for the green economy. Latvia data (Source: Eurostat (2019), OECD (2019), World Bank (2019) data)

The data that characterize the situation in Estonia are presented in Figure 4. The available data allow us to assume that the development of the green economy in Estonia is exceptionally significant, and comparing the data of 2018 among the 3 Baltic States, Estonia has the highest green economy index $(0.65)$.

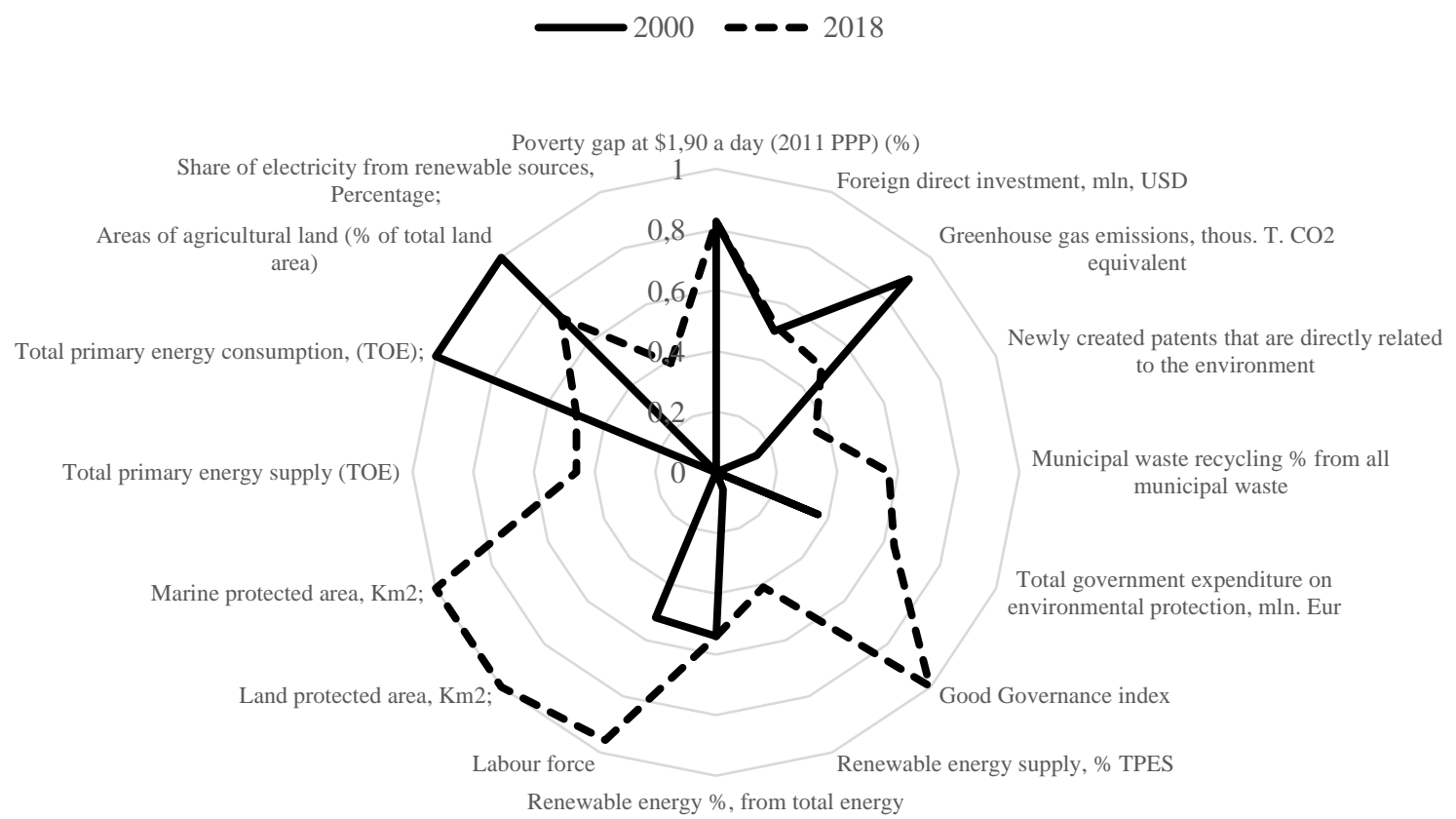

Fig. 4. Normalized indicators for the green economy. Estonia data (Source: Eurostat (2019), OECD (2019), World Bank (2019) data) 
This result is due to the positive change in most indicators. Indicators that have a positive change are protected areas, primary energy supply, primary energy consumption, renewable energy supply, government spending on environmental protection, municipal waste recycling, new patents, greenhouse gas emissions.

Although the development of the green economy in Estonia is considered strong, there are opportunities for development. As in other countries of the Baltic region, the issue of poverty is important in Estonia - there is no significant change during the analysed period. The development of renewable energy supply and production in Estonia is very strong, but the share of renewable energy in the country may account for a larger share. For this reason, a new development opportunity is envisaged, which would allow attracting additional foreign direct investment.

\section{Conclusions}

Assessing the circular economy is a complex task. The analysis of the scientific literature revealed many indicators for the evaluation of the green economy, but in comparison, the identified indicators are quite similar - economic indicators such as GDP, investment, available capital, social indicators such as employability, urbanization and technology are analysed. On the other hand, their number and detail in research vary widely. It follows that the green economy covers the whole set of research areas and evaluation indicators. Indicators measured over time describe the structural characteristics and quantitative changes of the green economy, and provides a new understanding of the opportunities and directions of green economy development.

In the framework of this study, fifteen indicators were selected for the analysis of green economy in the Baltic States. The normalization and further evaluation of these indicators from the point of view of the green economy allowed to determine the significance of individual social, economic and environmental dimensions for the overall green economy index and to show the changes over a period. All macroeconomic and environmental data are collected from publicly available databases: Eurostat, OECD and World Bank. Some data are provided non-periodically. For indicator data series where data gaps are identified, the arithmetic mean of the existing indicator data series will be added. The collected data also form the basis for further in-depth prognostic studies.

The results showed that in all the analysed countries, a strong growth of green economy development indices can be seen, in Estonia they remained the best among the three Baltic countries during the analysed period. An analysis of which individual indicators are most important in the development of the green economy and have the greatest significance for the index has shown that their estimates and position have changed significantly in less than two decades. In 2000, the highest positions in Lithuania were in terms of greenhouse gas emissions, labour force and agricultural land, in Latvia - primary energy and greenhouse gas emissions, and in Estonia - primary energy and agricultural land. According to the data of 2018, the most significant areas in Lithuania, Latvia and Estonia have become protected marine and land indicators. In Latvia, the indicators of good governance also stood out among the highest, while in Estonia the indicators of good governance and labour force stood out.

\section{References}

Abu Jamie N. (2018). Financing Green Economy Impact on Sustainable Development. International Journal of Business Administration, 9(2), 123-128.

Barbier E.B., Markandya A. (2013). A New Bluepring for a Green Economy. Routledge, New York.

D'Amato D., Droste N., Allen B., Kettunen M., Lähtinen K., Korhonen J., Leskinen P., Matthies B.D., Toppinen A. (2017). Green, circular, bio economy: A comparative analysis of sustainability avenues. Journal of cleaner production (168), 716-734. Available from Internet: https://doi.org/10.1016/j.jclepro.2017.09.053

European Commission (2018). Reference Document No 25. The inclusive green economy in EU development

Eurostat (2019). Database. Available from Internet: https://ec.europa.eu/eurostat/data/database

Fankhauser S., Kazaglis A. and Srivastav S. (2017). Green Growth Opportunities for Asia. Asian Development Bank. Available from Internet: http://dx.doi.org/10.22617/WPS178639-2 
Gultekin O.F., Erenoglu B. 2018. A research on policies for green economy in developed and developing countries within the scope of sustainable development. Challenges of the Knowledge Society 12(-), 852-856. Available from Internet: https://doaj.org/article/b2fd15f8b3bf455c98e5f275d0a74b7f

Holger S., Sandra V., Jurger-Friedrich H. (2017). Green Economy Innovation Index (GEII) - a normative innovation approach for Germany \& its FEW Nexus. Energy Procedia, 142, 2310-2316. Available from Internet: https://doi.org/10.1016/j.egypro.2017.12.159

International Chamber of Commerce (2012). Green economy roadmap. A guide for business, policymakers, and society. Available from Internet: https://iccwbo.org/content/uploads/sites/3/2012/08/Green-Economy-Roadmapa-guide-for-business_-policy-makers-and-society.pdf

Islam R.M., Siwar C., Ludin N.A., Chowdhury M.S., Ibrahim Y. (2012). Green economy: assessing the greenness of the Malaysian economy. International Journal of Green Economics, 6(3). Available from Internet: https://doi.org/10.1504/IJGE.2012.050972

Kang H. (2013). The prevention and handling the missing data. Korean J Anesthesiol, 65 (5), $402-406$. 10.4097/kjae.2013.64.5.402

Kunapatarawong R. and Martinez-Ros E. (2016). Towards green growth: How does green innovation affect employment? Research Policy, 45, 1218-1232. Available from Internet: http://dx.doi.org/10.1016/j.respol.2016.03.013

Law A., De Lacy T., Lipman G., \& Jiang M. (2016). Transition to a green economy: the case of tourism in Bali, Indonesia. Journal of Cleaner Production 111, 295-305. Available from Internet: https://doi.org/10.1016/j.jclepro.2014.12.070

Loiseau E., Saikku L., Antikainen R., Droste N., Hansjurgens B., Pitkanen K., Leskinen P., Kuikman P., \& Thomsen M. (2016). Green economy and related concepts: An overview. Journal of Cleaner Production 139, 361371. Available from Internet: https://doi.org/10.1016/j.jclepro.2016.08.024

Maran R.M., \& Nedelea A.M. (2017). Green economy: chalanges and opportunities. Ecoforum, 6(3). Available from Internet: https://doaj.org/article/12667f98fd3b43aaa8308fbe58c5f4fb

Moyo T., (2014). Green economy/growth policies and their implementation in the context of the renewable energy sector: The case of Mozambique, South Africa and Zimbabwe. International Journal of African Renaissance Studies - Multi-, Inter- and Transdisciplinarity, 9(2), 39-60. Available from Internet: https://doi.org/10.1080/18186874.2014.987954

Nahman A., Mahumani B.K. and de Lange W.J. (2016). Beyond GDP: Towards a Green Economy Index. Development Souther Africa, 33(2), 215-233. Available from Internet: https://doi.org/10.1080/0376835X.2015.1120649

Nieto J., Carpintero O., Miguel L. J. (2018) Less than 2 oC? An Economic - Enviromental Evaluation of the Paris Agreement. Ecological Economics 146, 69-84. Available from Internet: https://doi.org/10.1016/j.ecolecon.2017.10.007

Organization for Economic Co-operation and Development (2019). Oecd.stat. Available from Internet: https://stats.oecd.org/

Pan W., Hu C., Tu H., Zhao C., Yu D., Xiong J. ir Zheng G. (2019). Assessing the Green Economy in China: An Improved Framework. Journal of Cleaner Production, 209 (1), 680-691. Available from Internet: https://doi.org/10.1016/j.jclepro.2018.10.267

Porfir'ev B.N. (2012). Green economy: Worldwide development trends and prospects. Herald of the Russian Academy of Sciences 82(2), 120-128. Available from Internet: https://doi.org/10.1134/S1019331612020074

Sonnenschein J., Mundaca L. (2015). Decarbonization under Green Growth Strategies? The case of South Korea. Journal of Cleaner Production, 123(1), 180-193. Available from Internet: https://doi.org/10.1016/j.jclepro.2015.08.060

Stankevičienè J., Nikanorova M. (2017). Analysis of Economic and Environmental Welfare in the Context of Circular Economy. In Contemporary Issues in Business, Management and Education, 2017 (87-96). Vilnius: VGTU press. Available from Internet: https://doi.org/10.3846/cbme.2017.052

The World bank Group. World Bank open data. Available from Internet: https://data.worldbank.org/

Unay-Gailhard and Bojnec (2019). The impact of green economy measures on rural employment: Green jobs in farms. Journal of Cleaner Production, 208, 541-551. Available from Internet: 
https://doi.org/10.1016/j.jclepro.2018.10.160

United Nations (1998). Kyoto protocol to the United Nations Framework Convention on Climate Change.

United Nations (2015). Paris Agreement. Available from Internet: https://unfccc.int/sites/default/files/english_paris_agreement.pdf

United Nations Climate Change (2019). Kyoto protocol - Targets for the first commitment period. Available from Internet: https://unfccc.int/process-and-meetings/the-kyoto-protocol/what-is-the-kyoto-protocol/kyoto-protocoltargets-for-the-first-commitment-period

United Nations Environmental Programme (2011). Working towards a Balanced and Illusive Green Economy: A United Nations System-wide perspective. Available from Internet: https://sustainabledevelopment.un.org/index.php?page=view\&type $=400 \& n r=652 \& m e n u=1515$

Weber and Cabras (2017). The Transition of Germany's Energy Production, Green Economy, Low - Carbon Economy, Socio - Environmental Conflicts, and Equitable Society. Journal of Cleaner Production, 167, 12221231. Available from Internet: https://doi.org/10.1016/j.jclepro.2017.07.223 